\title{
Effect of Adenotonsillectomy on Attention in Korean Children With Sleep-Disordered Breathing
}

\author{
Min Jae Kim ${ }^{1}$. Sung Hee Bae ${ }^{1}$ S Sung Min Lee ${ }^{1}$ Kang Hyun Lee ${ }^{1}$ Dong-Kyu Kim ${ }^{1,2}$ \\ ${ }^{1}$ Department of Otorhinolaryngology-Head and Neck Surgery, Chuncheon Sacred Heart Hospital, Hallym University College of Medicine, \\ Chuncheon; ${ }^{2}$ Institute of New Frontier Research, Hallym University College of Medicine, Chuncheon, Korea
}

Objectives. Pediatric sleep-disordered breathing (SDB) is a common debilitating disorder that can adversely affect the attention and academic performance of school-age children. Unfortunately, only a few studies have examined the effect of SDB treatment on attention in pediatric populations. Therefore, the aim of this study was to prospectively investigate the effect of SDB treatment on attention in children.

Methods. This study consecutively enrolled SDB children with adenotonsillar hypertrophy. All subjects underwent standard-of-care treatment (adenotonsillectomy or close observation) and were evaluated using a computerized comprehensive attention test at the initial visit. Comprehensive attention tests consisted of both sustained and divided attention tasks. Each completed task was assigned an attention score, which was based on the number of omission or commission errors. The comprehension attention test was repeated 1 year later.

Results. A total of 171 children who underwent adenotonsillectomy and 32 children who did not undergo adenotonsillectomy were included in this study. At baseline, there was no significant difference according to the score of all type comprehension attention tests between children in the adenotonsillectomy group and in the observation group. One year after treatment, children in the adenotonsillectomy group had significantly improved scores in all attention tasks. Children in the observation group had only significant improvement in omission errors on sustained attention tasks. Meanwhile, the attention score based on commission errors of divided attention tasks was significantly worse than at baseline for those.

Conclusion. Our study showed that adenotonsillectomy may be helpful in improving attention in children with SDB.

Keywords. Adenoidectomy; Tonsillectomy; Attention; Sleep Apnea; Child

\section{INTRODUCTION}

Pediatric sleep-disordered breathing (SDB) describes a spectrum of breathing abnormalities, including loud snoring, gasping, upper airway resistance syndrome, and obstructive sleep apnea. This common debilitating disorder, which causes sleep disruption, can have adverse behavioral and neurocognitive conse-

\footnotetext{
- Received January 29, 2018

Revised February 23, 2018

Accepted March 7, 2018

- Corresponding author: Dong-Kyu Kim

Department of Otorhinolaryngology-Head and Neck Surgery, Chuncheon Sacred Heart Hospital, Hallym University College of Medicine, 77 Sakju-ro, Chuncheon 24253, Korea

Tel: +82-33-240-5180, Fax: +82-33-241-2909

E-mail: doctordk@naver.com
}

quences. Previous studies have confirmed that SDB is associated with increased incidences of depression, inattention, and hyperactivity and dysfunction in memory, executive functioning, and general intelligence [1-3]. Furthermore, a recent meta-analysis study showed that school-age children with SDB may have poorer academic performance than their counterparts without SDB [4].

The development of SDB in children is associated with multiple factors, including adenotonsillar hypertrophy, allergic rhinitis, obesity, and craniofacial abnormalities. Among those, adenotonsillar hypertrophy is known as a major cause in SDB symptoms and it could be easily improved by simple adenotonsillectomy in most cases. In confirmation, multiple studies have shown that adenotonsillectomy improved behavioral and neurocognitive deficits in children with SDB [5-7]. Unfortunately,

Copyright @ 2018 by Korean Society of Otorhinolaryngology-Head and Neck Surgery.

This is an open-access article distributed under the terms of the Creative Commons Attribution Non-Commercial License (http://creativecommons.org/licenses/by-nc/4.0)

which permits unrestricted non-commercial use, distribution, and reproduction in any medium, provided the original work is properly cited. 
these studies largely utilized subjective measures and the effect of adenotonsillectomy on objective behavioral and neurocognitive measures has not been sufficiently examined in children with SDB. Additionally, most studies examining the effects of SDB were performed on Western children, who may be affected differently than Asian children.

Therefore, the present study objectively examined the effect of adenotonsillectomy on attention in Korean children with SDB. Children with SDB who did not undergo an adenotonsillectomy were also included to serve as a comparison group.

\section{MATERIALS AND METHODS}

\section{Participants}

This study included consecutive subjects who visited our pediatric SDB clinic because of habitual mouth breathing, snoring, or sleep apnea, and simultaneously had adenotonsillar hypertrophy, between May 2013 and February 2016. All subjects underwent standard-of-care examination and treatment and all clinical data used in this study were obtained from the medical records. However, attention data were prospectively obtained through study-related attention testing. Subjects were excluded from study participation if any of the following were true: younger than 4 years and older than 9 years of age, history of attention deficit/hyperactivity disorder or other psychological disorder, presence of hearing or vision deficits according to their parent's comments, body mass index (BMI) at or above the 95th percentile, positive result of skin prick test (SPT) for the evaluation of allergic rhinitis, or diagnosis of a craniofacial syndrome or neuromuscular disease. The study protocol was approved by the Institutional Review Board of Chuncheon Sacred Heart Hospital (IRB No. 2016-50) and, all study subjects provided written informed consent to participate in the study. All study conduct adhered to the tenets of the Declaration of Helsinki.

\section{Evaluation of nasal symptoms}

All caregivers were asked to complete a nasal symptom questionnaire at the initial clinic visit. The total nasal symptom score (TNSS) was determined based on the following four items: rhi-

\section{H I G H L I G H T S}

- Adenotonsillectomy may be effective on the improvement of attention in Korean sleep-disordered breathing children who have adenotonsillar hypertrophy.

- All types of attention scores, such as sustained and divided attention are improved in the adenotonsillectomy group.

- When practicing sleep-disordered breathing children, we need to closely evaluate and routine correction of adenotonsillar hypertrophy may be recommended. norrhea, sneezing, itchy nose, and nasal obstruction. Caregivers also completed a questionnaire regarding the number of upper respiratory infections (URIs) their child had experienced within the past year. The Korean version of the obstructive sleep apnea-18 (KOSA-18) score test was also administered to parents/ guardians. Based on these data, children underwent adenotonsillectomy or were treated with close observation. For example, we recommended close observation for the children who showed a relatively lower score on the questionnaires, including the number of URIs, TNSS, or KOSA-18. Children who did not undergo adenotonsillectomy were treated with close monitoring of symptoms and were treated on an as-needed (e.g., URI medication) basis for 1 year.

\section{Evaluation of adenotonsillar hypertrophy and allergic rhinitis}

All patients were examined by the same pediatric sleep surgeon (DKK). All subjects had their adenotonsillar hypertrophy graded based on oropharyngeal endoscopy and lateral cephalometry findings. Palatine tonsil size was graded using the Friedman staging system [8]. The ratio of the adenoids to the nasopharyngeal airway was defined as the ratio of the adenoid thickness to the nasopharyngeal airway width, as previously described [9], and was graded using the following 4-point system: grade 1, $0 \%-$ $25 \%$; grade $2,25 \%-50 \%$; grade $3,50 \%-75 \%$; and grade 4 , $75 \%-100 \%$. Adenotonsillar hypertrophy was defined as grade 3 or 4 hypertrophy of the palatine tonsils and/or adenoids [10]. The presence/absence of allergic rhinitis was determined using specific allergen tests, including the SPT. The SPT was performed using standardized extracts (Allergopharma, Reinbek, Germany) from 13 common aeroallergens, including house dust mites (Dermatophagoides pteronyssinus, Dermatophagoides farinae), mold (Aspergillus fumigatus, Alternaria alternata), animal dander (cat epithelia, dog epithelia), pollen (tree pollen mixture I, tree pollen mixture II, oak, grass pollen mixture, mugwort, and ragweed), and cockroach (Blattella germanica).

\section{Comprehensive attention testing}

Attention was evaluated using the computerized comprehensive attention test (CAT), which was developed by the Korean Academy of Child and Adolescent Psychiatry. The computerized CAT for sustained and divided attention was performed using previously described methods [11-13]. Briefly, the sustained attention task assessed the ability to maintain consistent behavioral responses during continuous and repetitive activities. Visual stimuli in various shapes were presented every 2 seconds for 10 minutes. Participants were instructed to respond to all shapes, except for the " $\mathrm{X}$ " shape. Therefore, the task measured the subject's capacity to inhibit responses to certain stimuli under sustained attention conditions. The divided attention task demanded more attention than the sustained attention task. Divided attention involves the ability to simultaneously respond to more than two tasks. In the divided attention task, auditory and visual 
stimuli were simultaneously presented every 2 seconds for 3 minutes 20 seconds. Participants were instructed to only respond when an auditory or visual stimulus was the same as that presented in the preceding pair of stimuli. The number of omission and commission errors was evaluated for each attention task. An omission error indicates inattention and was defined as the failure to respond to a target. A commission error indicates impulsivity and was defined as an inappropriate response to a stimulus. Potential confounding factors were removed by adjusting the computerized CAT results to those of a standard sexand age-matched population. The standard population had attention task scores with a mean of 100 and a standard deviation of 15 .

\section{Statistical analysis}

Data are presented as mean \pm standard deviation unless otherwise specified. Independent $t$-tests and chi-square tests were used to determine the statistical significance of differences in general characteristics between children in the adenotonsillectomy and observation groups. In addition, paired $t$-tests were used to compare repeated computerized CAT results within treatment groups. All statistical analyses were performed using IBM SPSS ver. 21.0 (IBM Corp., Armonk, NY, USA) and statistical significance was defined as $P<0.05$.

\section{RESULTS}

\section{Subject characteristics}

A total of 160 children were initially enrolled in the study. Mean subject age was $6.5 \pm 1.7$ years (range, 4 to 9 years) and 109 participants $(68.1 \%)$ were male. A total of 138 children $(86.3 \%)$ were in the adenotonsillectomy group and 22 children $(13.7 \%)$ were in the observation group. The clinical characteristics of each study group are summarized in Table 1 . There were no sig- nificant differences between the groups in age, sex ratio, BMI, or size of the adenoid and tonsil, the number of URIs, mean TNSS score, and mean KOSA-18 scores. In addition, on children with adenotonsillectomy, the mean total scores for KOSA-18 on 1-year follow-up (after surgery) were significantly lower than those for KOSA-18 on baseline (before surgery; 60.2 to 33.0, $P<0.001)$. However, there was no significant difference of the mean total KOSA-18 score in children without adenotonsillectomy between baseline and 1-year follow-up (66.0 and 62.1, respectively).

\section{Baseline attention status}

The baseline computerized CAT result for sustained attention was $88.3 \pm 21.3$ based on omission errors and $90.0 \pm 15.0$ based on commission errors in the observation group and $90.8 \pm 21.6$ based on omission errors and $90.6 \pm 14.3$ based on commission errors in the adenotonsillectomy group. There was no significant difference of any types of sustained attention scores between two groups (Fig. 1).

Table 1. General characteristics of subjects

\begin{tabular}{lccc}
\hline Variable & $\begin{array}{c}\text { Children without } \\
\text { adenotonsillectomy } \\
(\mathrm{n}=22)\end{array}$ & $\begin{array}{c}\text { Children with } \\
\text { adenotonsillectomy } \\
(\mathrm{n}=138)\end{array}$ & P-value \\
\hline Age $(\mathrm{yr})$ & $6.5 \pm 1.6$ & $6.5 \pm 1.7$ & 0.981 \\
Male sex & $14(63.6)$ & $95(69.6)$ & 0.629 \\
BMl $\left(\mathrm{kg} / \mathrm{m}^{2}\right)$ & $16.8 \pm 2.6$ & $16.4 \pm 2.1$ & 0.567 \\
Adenoid & $2.7(0.8)$ & $2.9(0.8)$ & 0.173 \\
Tonsil & $3.3(0.7)$ & $3.1(0.9)$ & 0.426 \\
Frequent URI & $8.1 \pm 5.0$ & $7.4 \pm 4.5$ & 0.545 \\
TNSS & $18.0 \pm 5.0$ & $16.6 \pm 8.5$ & 0.491 \\
KOSA-18 & $66.0 \pm 14.6$ & $60.2 \pm 14.0$ & 0.100 \\
\hline
\end{tabular}

Values are presented as mean \pm standard deviation or number (\%).

BMI, body mass index; URI, upper respiratory infection; TNSS, total nasal symptom score; KOSA-18, Korean version of the obstructive sleep apnea-18.

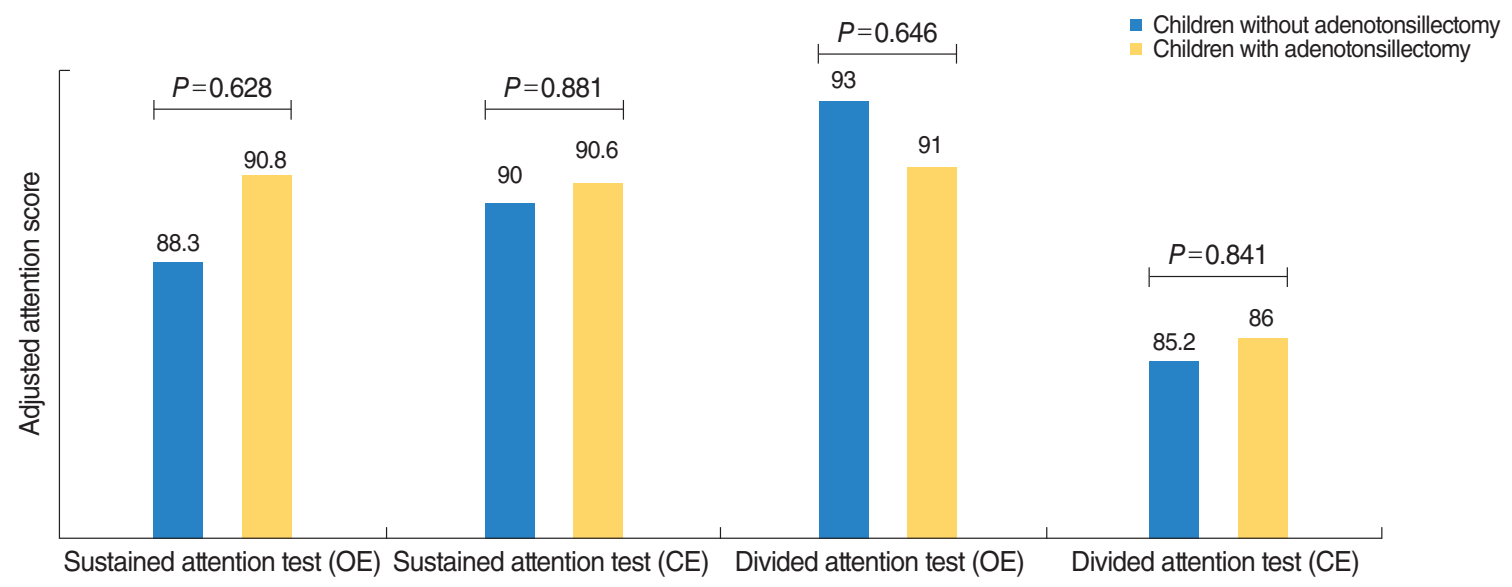

Fig. 1. Comparisons of comprehensive attention test results between children without and with adenotonsillectomy groups on baseline. OE, omission errors; CE, commission errors. 


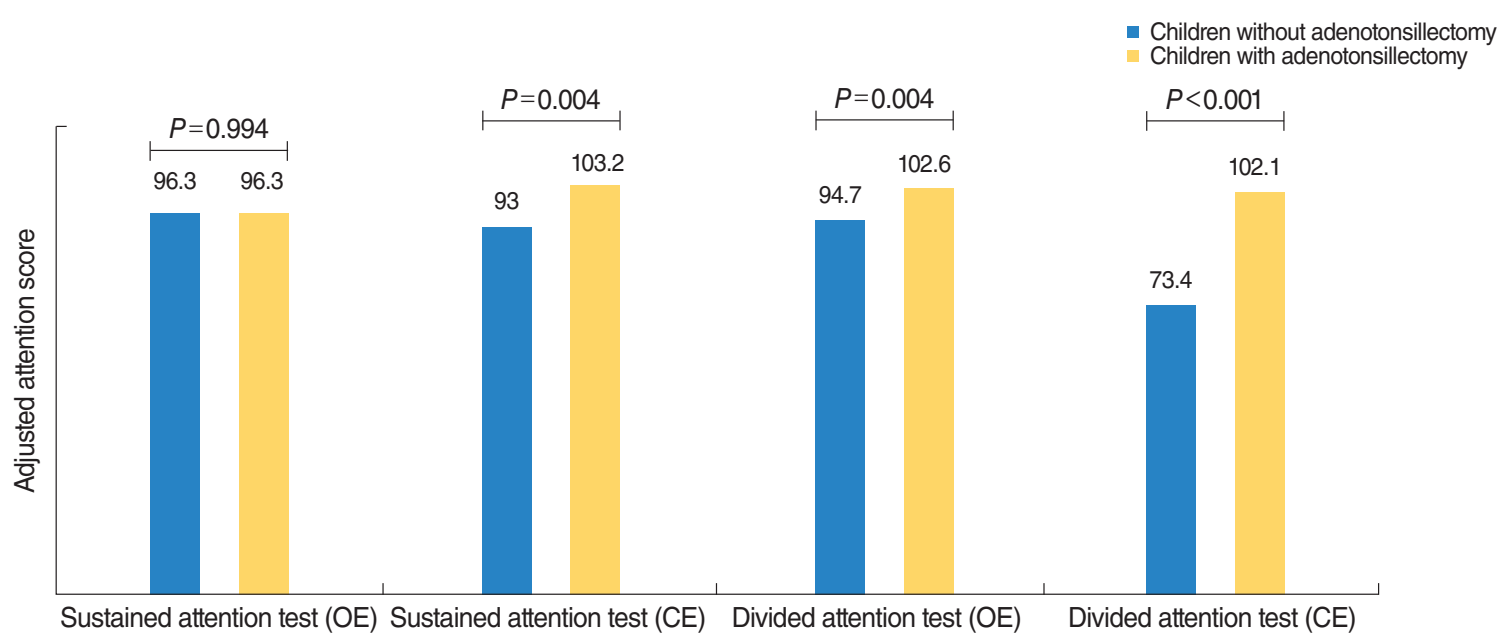

Fig. 2. Comparisons of comprehensive attention test results between children without and with adenotonsillectomy groups on 1-year follow-up. $\mathrm{OE}$, omission errors; $\mathrm{CE}$, commission errors.

Table 2. Comparisons of comprehensive attention test results between baseline and 1-year follow-up data in children without adenotonsillectomy

\begin{tabular}{lcll}
\hline $\begin{array}{l}\text { Children without } \\
\text { adenotonsillectomy }(\mathrm{n}=32)\end{array}$ & Baseline & $\begin{array}{c}\text { 1-year } \\
\text { follow-up }\end{array}$ & $P$-value \\
\hline $\begin{array}{l}\text { Sustained attention test } \\
\quad \text { Omission errors }\end{array}$ & $88.3 \pm 21.3$ & $96.3 \pm 8.6$ & 0.101 \\
$\quad$ Commission errors & $90.0 \pm 15.0$ & $93.0 \pm 14.1$ & 0.409 \\
$\begin{array}{l}\text { Divided attention test } \\
\quad \text { Omission errors }\end{array}$ & $93.0 \pm 13.3$ & $94.7 \pm 10.1$ & 0.654 \\
Commission errors & $85.2 \pm 16.7$ & $73.4 \pm 18.1$ & 0.034 \\
\hline
\end{tabular}

Values are presented as mean \pm standard deviation.

The baseline computerized CAT result for divided attention was $93.0 \pm 13.3$ based on omission errors and $85.2 \pm 16.7$ based on commission errors in the observation group and $91.0 \pm 19.8$ based on omission errors and $86.0 \pm 18.7$ based on commission errors in the adenotonsillectomy group. Children in the observation group had higher attention scores based on omission errors $(P=0.646)$ and lower attention scores based on commission errors $(P=0.841)$ than children in the adenotonsillectomy group, but these differences were not significant (Fig. 1).

\section{Effect of adenotonsillectomy on attention status}

On 1-year follow-up, the commission errors of sustained attention and the omission/commission errors of divided attention showed a significant difference between observation group and adenotonsillectomy group (Fig. 2). The CAT results were compared between baseline and 1 year to investigate the effect of adenotonsillectomy on attention. Children in the observation group showed a significant worseness in divided attention task score based on commission errors $(P=0.034)$, but no change in sustained attention task score based on commission errors $(P=0.409)$ (Table 2). For the omission errors in sustained and divided attention, children in the observation group had no signifi-
Table 3. Comparisons of comprehensive attention test results between baseline and 1-year follow-up data in children with adenotonsillectomy

\begin{tabular}{lrrr}
\hline $\begin{array}{l}\text { Children with } \\
\text { adenotonsillectomy }(n=171)\end{array}$ & Baseline & $\begin{array}{c}\text { 1-year } \\
\text { follow-up }\end{array}$ & $P$-value \\
\hline $\begin{array}{l}\text { Sustained attention test } \\
\text { Omission errors }\end{array}$ & $90.8 \pm 21.6$ & $96.3 \pm 12.6$ & 0.012 \\
$\quad \begin{array}{lll}\text { Commission errors } \\
\text { Divided attention test }\end{array}$ & $90.6 \pm 14.3$ & $103.2 \pm 13.0$ & $<0.001$ \\
Omission errors & $91.0 \pm 19.8$ & $102.6 \pm 16.3$ & $<0.001$ \\
Commission errors & $86.0 \pm 18.7$ & $102.1 \pm 9.0$ & $<0.001$ \\
\hline
\end{tabular}

Values are presented as mean \pm standard deviation.

cant change between baseline and 1-year follow-up $(P=0.101$ and $P=0.654)$. In contrast, children in the adenotonsillectomy group had significantly higher scores at 1 year (both omission error- and commission error-based scores) for both sustained and divided attention tasks (Table 3).

\section{DISCUSSION}

The symptoms of SDB, which is prevalent in children, include obstructive sleep apnea and frequent loud snoring, snorting, or gasping. Pediatric SDB is also associated with daytime functioning deficits in cognitive performance and behavioral regulation. Previous studies have also suggested that SDB in children negatively impacts school performance [14-16]. However, the causal relationship between pediatric SDB and neurobehavioral performance has not been firmly established. It has been suggested that SDB in childhood results in a decreased arterial blood oxygen saturation, and subsequent intermittent episodes of brain hypoxemia [17-19]. Therefore, sleep disturbances may play a role in altering attention in the pediatric population.

Adenotonsillar hypertrophy is a major contributor to SDB in 
children. As a result, tonsil removal generally leads to significant improvements in SDB symptoms. In addition, several studies have indicated that hearing or visual problems, obesity, allergic rhinitis, craniofacial abnormalities, and impaired upper airway patency neural control are associated with pediatric SDB [2022]. Therefore, because attention deficits are known to be multifactorial, the current study was specifically designed to isolate and identify the effects of adenotonsillectomy on attention in children with SDB and adenotonsillar hypertrophy. Attention scores of study subjects were adjusted for potential confounding factors (e.g., sex and age) and patients with conditions known to affect attention (i.e., hearing or visual problems, obesity, allergic rhinitis, craniofacial abnormalities, and impaired upper airway patency neural mechanisms) were excluded.

In the present study, observation group was defined as when the physician recommended surgery, but the patient's caregiver chose to follow up and we examined the relationship between adenotonsillectomy and attention (sustained and divided) in children with SDB. We found that the observation group has no any significant improvement of any types of attention test. However, the sustained and divided attention scores based on omission and commission errors increased in children in the adenotonsillectomy group. Moreover, 1 year after the initial visit, children in the observation group had a decrease from baseline in divided attention task scores based on commission errors. This result suggests that adenotonsillectomy may be more beneficial to SDB children with adenotonsillar hypertrophy, as opposed to close monitoring with on-demand medical treatment. Interestingly, we used the computerized CAT as an objective measure of attention, which has both sustained and divided attention tasks and is based on omission and commission errors. Sustained attention is defined as the ability to direct and focus cognitive activity on specific stimuli for a sustained period of time (e.g., reading a newspaper article) $[23,24]$. Thus, in order to complete any cognitively planned activity or thought, one must use sustained attention. In contrast, divided attention is required to actively pay attention to two or more tasks at the same time (e.g., reading an email while listening to someone talk, simultaneously watching television and surfing the internet) $[25,26]$. Therefore, divided attention requires more concentration than sustained attention.

Our study showed that adenotonsillectomy was more effective in improving divided attention than observation in children with SDB. This suggests that appropriate treatment of pediatric SDB is beneficial for improving attention and that, SDB children with adenotonsillar hypertrophy and adenotonsillar hypertrophy should be considered for early surgical intervention to resolve SDB symptoms. One randomized study showed that cognitive scores improved significantly more in subjects who had undergone adenotonsillectomy than in those who had simply been observed [27]. Another controlled prospective cohort study found a reduction in omission and commission errors in children who had undergone adenotonsillectomy, but not in children who had not [28]. However, some studies showed that attention was not significantly changed by adenotonsillectomy $[29,30]$. One of these studies demonstrated improvements in respiratory parameters and snoring frequency following adenotonsillectomy, but neurocognitive performance was not affected differently than in the observation group [29]. The other study examined children with obstructive sleep apnea and found no difference between the adenotonsillectomy and observation groups in attention or executive function improvements, as measured by neuropsychological testing [30].

Advantages of the present study were that it used objective measures of attention, had a longitudinal design, and ruled out allergic rhinitis; it is well known that pediatric allergic rhinitis is associated with a poor attention status. However, our study had several limitations. First, our subjects were not randomly placed into the treatment and control groups. Second, a selection bias may have been introduced into our data because our cohort was hospital-based. However, this may have been partially overcome because of our study's prospective design. Third, our study did not account for socioeconomic status or parental education, both of which are known to influence a child's attention status. Fourth, in addition to adenotonsillectomy, variable confounding factors can have an effect on the 1-year follow-up CAT results. Finally, in this study, we did not perform the full-night polysomnography on all children to detect for the presence of OSA in this study. Only 33 children (16.3\%) performed the full-night polysomnography due to high cost. The diagnosis of pediatric SDB in the present study was performed by using clinical examination (tonsillar or adenoid hypertrophy) and symptoms of snoring/apnea announced by caregiver.

In conclusion, our study suggests that Korean children who have adenotonsillar hypertrophy and SDB-associated attention problems could be helped by treatment with an adenotonsillectomy. In fact, both sustained and divided attention was improved in the adenotonsillectomy group. Therefore, regular evaluation and routine correction of adenotonsillar hypertrophy may be warranted, particularly in Korean children with SDB and attention problems.

\section{CONFLICT OF INTEREST}

No potential conflict of interest relevant to this article was reported.

\section{ACKNOWLEDGMENTS}

This research was supported by Hallym University Research Fund 2017 (HURF-2017-56), Chuncheon, Republic of Korea. 


\section{REFERENCES}

1. Rosen CL, Storfer-Isser A, Taylor HG, Kirchner HL, Emancipator JL, Redline S. Increased behavioral morbidity in school-aged children with sleep-disordered breathing. Pediatrics. 2004 Dec;114(6):1640-8.

2. Chervin RD, Archbold KH, Dillon JE, Panahi P, Pituch KJ, Dahl RE, et al. Inattention, hyperactivity, and symptoms of sleep-disordered breathing. Pediatrics. 2002 Mar;109(3):449-56.

3. Lande MB, Hooper SR, Batisky DL, Kupferman JC, Szilagyi PG, Samuels JA, et al. Sleep disordered breathing as measured by SRBD-PSQ and neurocognition in children with hypertension. Am J Hypertens. 2015 Apr;28(4):552-8.

4. Galland B, Spruyt K, Dawes P, McDowall PS, Elder D, Schaughency E. Sleep disordered breathing and academic performance: a metaanalysis. Pediatrics. 2015 Oct;136(4):e934-46.

5. Galland BC, Dawes PJ, Tripp EG, Taylor BJ. Changes in behavior and attentional capacity after adenotonsillectomy. Pediatr Res. 2006 May;59(5):711-6.

6. Mitchell RB, Boss EF. Pediatric obstructive sleep apnea in obese and normal-weight children: impact of adenotonsillectomy on qualityof-life and behavior. Dev Neuropsychol. 2009;34(5):650-61.

7. Li HY, Huang YS, Chen NH, Fang TJ, Lee LA. Impact of adenotonsillectomy on behavior in children with sleep-disordered breathing. Laryngoscope. 2006 Jul;116(7):1142-7.

8. Friedman M, Ibrahim H, Bass L. Clinical staging for sleep-disordered breathing. Otolaryngol Head Neck Surg. 2002 Jul;127(1):13-21.

9. Kim SY, LeeWH, Rhee CS, Lee CH, Kim JW. Regrowth of the adenoids after coblation adenoidectomy: cephalometric analysis. Laryngoscope. 2013 Oct;123(10):2567-72.

10. Kim DK, Rhee CS, Yun PY, Kim JW. Adenotonsillar hypertrophy as a risk factor of dentofacial abnormality in Korean children. Eur Arch Otorhinolaryngol. 2015 Nov;272(11):3311-6.

11. Kim SJ, LeeYJ, Cho SJ, Cho IH, LimW, LimW. Relationship between weekend catch-up sleep and poor performance on attention tasks in Korean adolescents. Arch Pediatr Adolesc Med. 2011 Sep;165(9): 806-12.

12. Kim DK, Rhee CS, Han DH, WonTB, Kim DY, Kim JW.Treatment of allergic rhinitis is associated with improved attention performance in children: the Allergic Rhinitis Cohort Study for Kids (ARCOKids). PLoS One. 2014 Oct;9(10):e109145.

13. Kim SJ, Lee YJ, Jang JH, Lim W, Cho IH, Cho SJ. The relationship between psychotic-like experiences and attention deficits in adolescents. J Psychiatr Res. 2012 Oct;46(10):1354-8.

14. Gozal D, Pope DW Jr. Snoring during early childhood and academic performance at ages thirteen to fourteen years. Pediatrics. 2001 Jun; 107(6):1394-9.

15. Montgomery-Downs HE, Jones VF, Molfese VJ, Gozal D. Snoring in preschoolers: associations with sleepiness, ethnicity, and learning. Clin Pediatr (Phila). 2003 Oct;42(8):719-26.

16. Urschitz MS, Guenther A, Eggebrecht E, Wolff J, Urschitz-Duprat
PM, Schlaud M, et al. Snoring, intermittent hypoxia and academic performance in primary school children. Am J Respir Crit Care Med. 2003 Aug;168(4):464-8.

17. Aljadeff G, Gozal D, Bailey-Wahl SL, Burrell B, Keens TG, Ward SL. Effects of overnight supplemental oxygen in obstructive sleep apnea in children. Am J Respir Crit Care Med. 1996 Jan;153(1):51-5.

18. Gozal D, Kheirandish-Gozal L. Sleep apnea in children: treatment considerations. Paediatr Respir Rev. 2006;7 Suppl 1:S58-61.

19. Kennedy JD, Blunden S, Hirte C, Parsons DW, Martin AJ, Crowe E, et al. Reduced neurocognition in children who snore. Pediatr Pulmonol. 2004 Apr;37(4):330-7.

20. Meltzer EO, Blaiss MS, Derebery MJ, Mahr TA, Gordon BR, Sheth $\mathrm{KK}$, et al. Burden of allergic rhinitis: results from the pediatric allergies in America survey. J Allergy Clin Immunol. 2009 Sep;124(3 Suppl):S43-70.

21. Chay OM, Goh A,Abisheganaden J,Tang J, Lim WH, Chan YH, et al. Obstructive sleep apnea syndrome in obese Singapore children. Pediatr Pulmonol. 2000 Apr;29(4):284-90.

22. Verhulst SL, Schrauwen N, Haentjens D, Suys B, Rooman RP, Van Gaal L, et al. Sleep-disordered breathing in overweight and obese children and adolescents: prevalence, characteristics and the role of fat distribution. Arch Dis Child. 2007 Mar;92(3):205-8.

23. Barkley RA. Behavioral inhibition, sustained attention, and executive functions: constructing a unifying theory of ADHD. Psychol Bull. 1997 Jan;121(1):65-94.

24. Stins JF, Tollenaar MS, Slaats-Willemse DI, Buitelaar JK, SwaabBarneveld H, Verhulst FC, et al. Sustained attention and executive functioning performance in attention-deficit/hyperactivity disorder. Child Neuropsychol. 2005 Jun;11(3):285-94.

25. Miller J. Divided attention: evidence for coactivation with redundant signals. Cogn Psychol. 1982 Apr;14(2):247-79.

26. Corbetta M, Miezin FM, Dobmeyer S, Shulman GL, Petersen SE. Selective and divided attention during visual discriminations of shape, color, and speed: functional anatomy by positron emission tomography. J Neurosci. 1991 Aug;11(8):2383-402.

27. Taylor HG, Bowen SR, Beebe DW, Hodges E, Amin R, Arens R, et al. Cognitive effects of adenotonsillectomy for obstructive sleep apnea. Pediatrics. 2016 Aug;138(2). pii: e20154458.

28. Abreu CB, Fuchs SC, Pascoto GR, Weber R, Guedes MC, Pignatari SS, et al. Effect of adenotonsillectomy on visual attention tests among children with sleep-disordered breathing: a controlled prospective cohort study. Clin Otolaryngol. 2013 Dec;38(6):487-93.

29. Kohler MJ, Lushington K, van den Heuvel CJ, Martin J, Pamula Y, Kennedy D. Adenotonsillectomy and neurocognitive deficits in children with sleep disordered breathing. PLoS One. 2009 Oct;4(10): e7343.

30. Brouillette RT. Adenotonsillectomy in childhood obstructive sleep apnea syndrome improves polysomnographic measures of breathing and sleep, but not attention and executive function. J Pediatr. 2013 Nov;163(5):1530-1. 